\title{
PERANCANGAN ILUSTRASI PADA CELANA JEANS SEBAGAI MEDIA KAMPANYE SOSIAL SUSTAINABLE FASHION UNTUK REMAJA PEREMPUAN USIA 18-21 TAHUN DI KOTA BANDUNG
}

\author{
Suci Fauziyah ${ }^{1}$, Eko Bambang Wisnu Nugroho ${ }^{2}$, Dewi Iriani ${ }^{3}$ \\ Program Studi Desain Komunikasi Visual, Sekolah Tinggi Teknologi Bandung1, 2, 3 \\ ekobambang@sttbandung.ac.id ${ }^{1,2,3}$
}

\begin{abstract}
Abstrak
Fesyen terus berkembang sejalan dengan majunya teknologi, berbagai macam bentuk, jenis, warna hingga motif muncul setiap musimnya dengan harga miring atau disebut juga dengan fast fashion. Dengan remaja perempuan sebagai kelompok yang kerap terpengaruh oleh gaya hidup konsumtif. Jeans merupakan produk fast fashion yang dimiliki banyak orang karena selain kuat juga menjadi produk fesyen basic yang bisa dipadupadankan dengan pakaian lainnya. Tetapi dari hal tersebut, dalam produksinya jeans membutuhkan banyak air dan mengkonsumsi banyak bahan kimia. Hal tersebut kemudian muncul sebuah istilah sustainable atau berkelanjutan, salah satunya dengan cara mendaur ulang kembali untuk dapat digunakan kembali melalui teknik upcycled. Yaitu sebuah teknik yang memanfaatkan barang-barang bekas untuk dapat digunakan kembali, dapat dilakukan dengan merubah bentuk atau pun menambahkan elemen lain seperti ilustrasi. Dalam prosesnya, perancangan ini menggunakan metode design thinking dengan tahapan awal berupa pengalaman empiris perancang, studi literatur, kuesioner dan wawancara. Hal tersebut dilakukan untuk menentukan rumusan masalah dan tujuan dari perancangan serta membantu dalam merancang konsep perancangan. Media yang digunakan adalah celana jeans bekas, yang kemudian digambar dengan teknik manual menggunakan cat akrilik, fabric medium dan spidol kain. Dalam pembuatannya, perancang melakukan tahap prototype dan test terlebih dahulu melalui eksperimen media pada celana jeans bekas. Seperti kekuatan warna pada media jeans, serta pencampuran warna yang akan digunakan sebagai warna dasar. Harapan kedepannya setelah perancangan ini dilaksanakan, perancang menyarankan kepada perancang selanjutnya untuk lebih kreatif dan inovatif dalam mengeksplore media lain selain jeans, dengan menggunakan jenis cat yang lebih sesuai dengan media yang digunakan. Sehingga barang-barang fesyen yang tidak terpakai dapat terpakai kembali. Bagi pembaca, diharapkan dapat memberikan informasi mengenai sustainable dan lebih bijak dalam berpakaian dengan sadar akan efek yang dihasilkan dari pakaian.
\end{abstract}

Kata kunci : Fast Fashion, Sustainable, Jeans Bekas, Upcycled, Ilustrasi

\section{Abstract}

The development of fashion is in line with the advancement of technology as various forms, types, colors, and motifs appear every season at low prices, or also called fast fashion. Adolescent girls are those often affected by their consumptive lifestyles. Jeans are fast fashion products that are owned by many people because in addition to being strong, it also serves as basic fashions that can be combined with other clothes. However, the production of jeans requires a lot of water and consumes a lot of chemicals. This brings forth a sustainable term, one of which is by recycling back using upcycled technique. This refers to a technique that utilizes used goods to be used again, which can be done by changing the shape or adding other elements, such as illustrations. In the process, this design used the method of design thinking with the initial stage came from the designer's empirical experiences, literature studies, questionnaires, and interviews. These were done to determine the formulation of the problem and the purpose of the design and to assist in concept designing. The media used are used jeans, which are then drawn using manual techniques of acrylic paint, fabric medium, and fabric marker. In the making, the designer did prototypes and test stages through experiments on used jeans to test the strength of the color of jeans and find the mixing colors that will be used as a base color. In the future, the designer suggests to the next designer to be more creative and innovative in exploring other media other than jeans, by using a kind of paint that is more suitable to the media used. Therefore, unused fashion products can be recycled. For readers, it is expected to provide information about sustainable and encouragement to be wiser in dressing by realizing the effects produced by clothing.

Keywords : Fast Fashion, Sustainable, Used Jeans, Upcycled, Illustration

\section{PENDAHULUAN}

Pakaian merupakan kebutuhan dasar manusia, yang saat ini bukan hanya berfungsi sebagai kain penutup badan, tetapi juga menjadi bagian dari penampilan dan gaya hidup dari pemakainya. Menurut KBBI atau Kamus Besar Bahasa Indonesia, pakaian dapat diartikan sebagai barang yang dipakai (baju, celana dan sebagainya)[5]. Selain menjadi kebutuhan, pakaian juga menjadi alat komunikasi tentang dirinya sendiri melalui pakaian yang digunakannya. Tetapi juga untuk menunjukkan nilai status berdasarkan pakaian yang dikenakan oleh individu tersebut1. Misalnya, saat seseorang memakai kemeja lengkap dengan dasi, jas, juga sepatu pantofel, orang yang melihat menilainya orang tersebut bekerja di kantor. Berbeda ketika melihat seseorang mengenakan kaus, celana jeans, serta sneaker. Orang yang melihat menilainya sebagai orang yang tengah berjalan-jalan biasa, walaupun belum tentu orang tersebut tengah jalan- jalan.

Kota Bandung sendiri terkenal dengan sebutannya sebagai kota fesyen di pulau Jawa sejak masa kolonial[1]. Tren fesyen di Kota Bandung pun terus berkembang dengan masyarakat mudanya yang ekspresif dalam berpakaian. Dilihat dari menjamurnya distro, factory outlet, butik sampai kawasan khusus fesyen yang tersebar di beberapa tempat. Misalnya denim, objek yang diangkat dalam penelitian ini, jenis kain ini banyak digunakan dalam produk fesyen dari celana, rok, jaket, tas. Bahkan sampai terdapat sentra khusus yang dapat ditemui di Kota Bandung, seperti di Gang Tamim ataupun 
Toko Tiga Bandung. Salah satu dari produk denim yang sering adalah celana jeans, mode sehari-hari yang melekat dengan aktivitas sebagian banyak orang dari dewasa, remaja sampai anak-anak.

Seiring berjalannya waktu, tren mode pun terus berkembang dengan cepat atau disebut dengan istilah fast fashion. Berbagai macam model bentuk, warna hingga motif ditawarkan. Misal, dari sepotong celana jeans saja terdapat banyak jenisnya, seperti boyfriend jeans, mom jeans, cropped jeans, skinny jeans, high waist jeans, straight-leg jeans, jeggings, low rise jeans, boot cut jeans, sampai flared jeans. Ditambah dengan perkembangan kemajuan digital yang membentuk perilaku konsumtif, hal ini tidak lepas dari industri yang memproduksi barang-barang secara massal, dibantu oleh media elektronik maupun massa sebagai bentuk promosi yang menarik minat beli konsumen[2].

Karena jeans merupakan produk fesyen yang tidak lekang oleh waktu sering juga digunakan dalam aktivitas seharihari. Upcycled pun dapat dilakukan dengan merubah bentuk ataupun menambahkan elemen lain untuk meningkatkan nilai pada pakaian, salah satunya adalah dengan ilustrasi. Memiliki fungsi sebagai dekorasi juga penjelas dari tulisan, ilustrasi pun banyak ditemukan pada produk jeans. Berdasarkan hal itu dalam penyusunan tugas akhir ini penulis memanfaatkan ilustrasi sebagai bentuk upcycled pada celana jeans lama. Untuk menyampaikan pesan, bahwasanya bukan tidak ada pakaian yang bisa dipakai, tetapi pakaian yang terlalu banyak untuk dipakai.

\section{TINJAUAN PUSTAKA}

1. Kampanye

Kampanye adalah sebuah rangkaian atau tindakan komunikasi yang terencana, dengan tujuan menciptakan efek tertentu kepada jumlah khalayak besar, dan dilakukan secara berkelanjutan pada kurun waktu tertentu[3]. Arti kampanye juga dapat diartikan sebagai sebuah upaya purposif untuk menginformasikan, menyakinkan atau memotivasi perubahan perilaku audience yang cukup terdefinisi dengan baik dan luas, umumnya untuk keuntungan nonkomersial bagi masyarakat atau masyarakat umumnya, dalam jangka waktu tertentu melalui kegiatan komunikasi teroganisasi yang melibatkan media massa dan internet serta sering dilengkapi dengan komunikasi interpersonal [3].

Sedangkan menurut KBBI, arti dari kampanye itu sendiri adalah gerakan (tindakan) serentak (untuk melawan, mengadakan aksi, dan sebagainya) juga sebagai kegiatan yang dilaksanakan oleh organisasi politik atau calon yang bersaing memperebutkan kedudukan dalam parlemen dan sebagainya untuk mendapat dukungan massa pemilih dalam suatu pemungutan suara[4].

\section{Remaja}

Remaja merupakan masa peralihan dari usia kanak- kanak menuju dewasa, periode individu mendekati puncak pertumbuhan fisik dan mentalnya. KBBI mengartikan bahwa remaja merupakan usia menuju dewasa[6]. Pada masa remaja ini ditandai dengan perubahan biologis, psikologis seperti berubahnya bentuk tubuh, dan perubahan emosinya[7]. Berikut merupakan perkembangan yang dialami remaja :

a. Perkembangan fisik, dengan berubahnya bentuk badan, tinggi badan juga berkembangnya otot tubuh.

b. Perkembangan seksual, munculnya tanda-tanda kelamin primer juga sekunder.

c. Perkembangan emosional

d. Perkembangan identitas diri

\section{Fashion}

Fashion atau fesyen dalam etimologi berasal dari bahasa Latin yaitu "factio" yang berarti membuat. Arti fesyen awalnya mengacu pada kegiatan, sesuatu yang dilakukan oleh seseorang. Berbeda dengan sekarang yang mengartikan fesyen sebagai sesuatu yang dikenakan oleh seseorang[4].

\section{KONSEP PERANCANGAN}

1. Segmentasi

a. Segmentasi Geografis

Melihat fashion yang berkembang di Kota Bandung dengan banyaknya tempat untuk membuat busana, sejalan dengan banyaknya pula tempat penjual busana di pusat perbelanjaan, factory outlet, distro hingga sentra khusus. Masyrakat mudanya yang kerap berpakaian modis dalam kesehariannya. Maka dari itu, dalam perancangan kampanye sosial ini menargetkan masyarakat muda yang tinggal di Kota Bandung sebagai tempat pelaksanaan kampanye. 


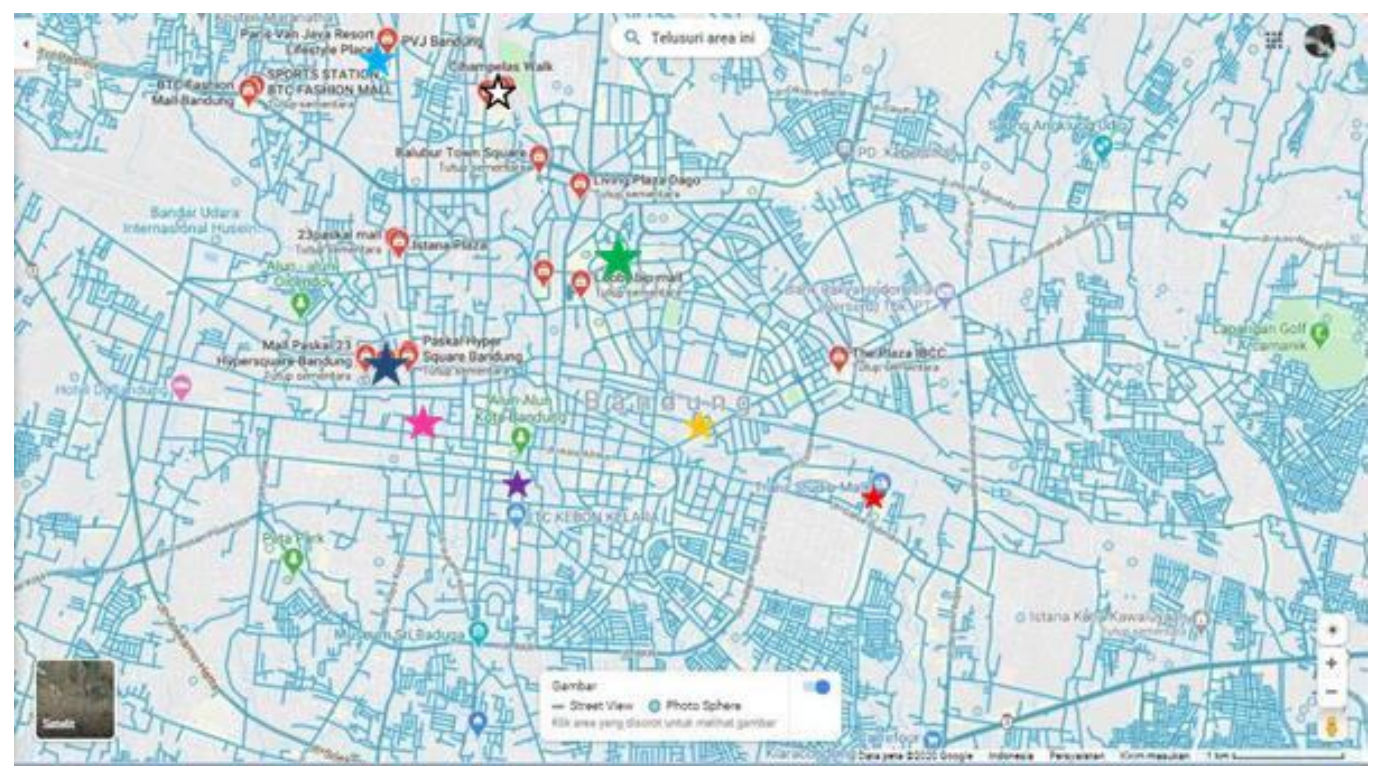

Gambar 1. Peta Kota Bandung via Google Maps

Keterangan:

1. 次: Daerah sekitaran Jalan Moh Toha, Jalan Dewi Sartika, Jalan Kepatihan terdapat beberapa toko-toko yang menjual aneka pakaian seperti Ria Busana, Grand Yogya Kepatihan, The Kings Shopping Center, Plaza Parahyangan.

2. : Jalan Ahmad Yani terdapat Toko Tiga Bandung yang menjual banyak aneka jeans

3. : Sekitaran Jalan Gatot Subroto terdapat Trans Studio Mall

4. J : Jalan Otto Iskandar Dinata terdapat deretan toko pakaian baik dari arah luar Pasar Baru maupun di dalamnya, juga terdapat Jalan Tamim yang banyak menjajakan bahan denim baik berupa lembaran kain ataupun produk jadinya.

5. Jalan Pasir Kaliki terdapat Paskal Hyper Square 23

6. Sekitaran Jalan Merdeka terdapat Dse Factory Outlet, Bandung Indah Plaza, Sekitaran Jalan R.E. Marthadinata dan Jalan Trunojoyo yang juga berjejer Factory Outlet juga Distro misalnya The Secret Factory Outlet, Gerai Outfit Bandung, Heritage The Factory Outlet, Cosmic Clothing dan lain-lain.

7. $\widehat{W}$ : Sederet Jalan Cihampelas yang banyak terdapat toko pakaian.

8. $\stackrel{1}{~: ~ S e k i t a r ~ J a l a n ~ S u k a j a d i ~ t e r d a p a t ~ P a r i s ~ V a n ~ J a v a ~ M a l l ~ j u g a ~}$ beberapa toko pakaian di pinggir jalannya. Gambar 2. Keterangan Peta Lokasi

b. Segmentasi Demografis

Dengan hasil kuesioner yang telah disebarkan, target kampanye ini adalah remaja perempuan berusia 18-21 tahun berstatus sebagai pelajar/mahasiswa/pekerja dengan status sosial menengah.

\section{c. Psikografis}

Gaya hidup dari target audiens kampanye sosial ini adalah, orang-orang yang dalam kesehariannya selalu memperhatikan penampilan, mengikuti tren berpakaian terbaru. Juga aktif mencari tau cara memadukan pakaian untuk digunakannya. Selain itu, target audiens dari kampanye ini adalah orang yang gemar berbelanja pakaian. Tipe target audiens yang dituju adalah perempuan yang tidak terlalu feminim dengan ciri dalam kesehariannya gemar memakai jeans highwaist yang dipadupadan dengan item fashion lain seperti kaos, kaos kaki, sepatu sneaker, dan totebag. 


\section{VISUALISASI KARYA}

\section{Art Work}

Dari beberapa media kreatif yang telah dibuat juga diteliti oleh penulis, media utama dari perancangan kampanye sosial sustainable fashion ini menggunakan ilustrasi pada jeans. Perancangan ini merupakan jenis perancangan karya desain. Tujuan dari kampanye sosial adalah untuk memperkenalkan sustainable fashion kepada remaja perempuan, juga untuk mengajak remaja perempuan di Kota Bandung untuk lebih menghargai pakaian lama dalam hal ini adalah jeans. Dengan memanfaatkan jeans sebagai benda fesyen yang dekat dengan keseharian target audiens, maka dipilihlah jeans sebagai media kampanye.

Proses dari perancangan ini dimulai dari analisis masalah, kemudian ide dan gagasan dengan membuat beberapa media alternatif untuk diseleksi, sampai didapatkannya media untuk perancangan kampanye sosial ini yaitu berupa ilustrasi jeans. Pada tahap awal dibuat sketsa melalui digital, kemudian dicetak pada kertas hvs lalu digunting untuk membuat pola yang sesuai dengan gambar ilustrasi yang akan diterapkan pada jeans. Proses perwarnaan menggunakan cat akrilik, spidol kain dan fabric medium. Pada tahap awal, dibuat moodboard dan sketsa perancangan untuk memudahkan proses dalam perancangan ini.

a. Moodboard

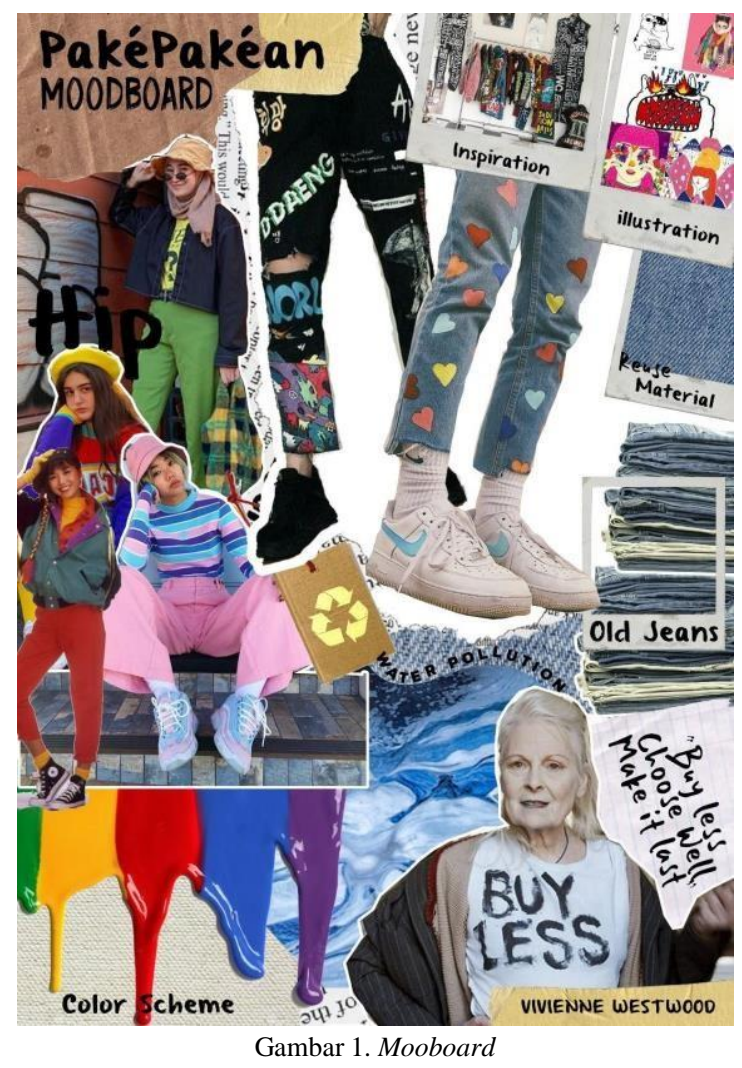

b. $\quad$ Logo

Jenis logo yang digunakan berupa logotype dengan bentuk yang dekoratif serta fun dengan ditunjukkan melalui bentuk yang melengkung. Pemilhan logotype didasari dengan banyaknya bentuk ilustrasi yang menempel pada media kampanye, sehingga logotype ini dipilih berbentuk tulisan. Dengan menggunakan font Arial yang kemudian didekroasikan menjadi bentuk berbeda dengan huruf yang sebenarnya. Selain itu pemilhan logotype ini, agar logo kampanye mudah diingat oleh target audience yang melihatnya. Dalam prosesnya logo dibuat secara digital melalui aplikasi Adobe Illustration atau AI.Logo dalam perancangan ini terinspirasi dari bentuk cat saat terjatuh pada bidang datar.

Citra yang ingin tampilkan dalam logo yang dibuat ini adalah colorfull and young dengan menggunakan warna-warna cerah pada tiap kata paké pakéan. Juga citra yang menunjukan jika kampanye ini menyenangkan untuk dilakukan. 


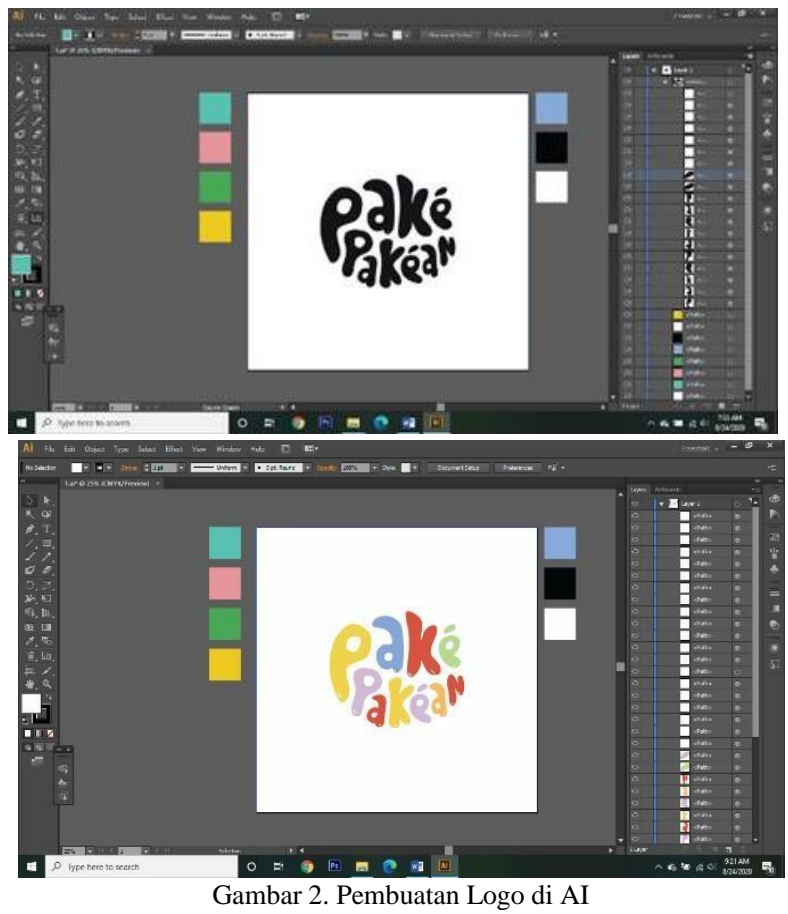

c. Sketsa Awal Perancangan

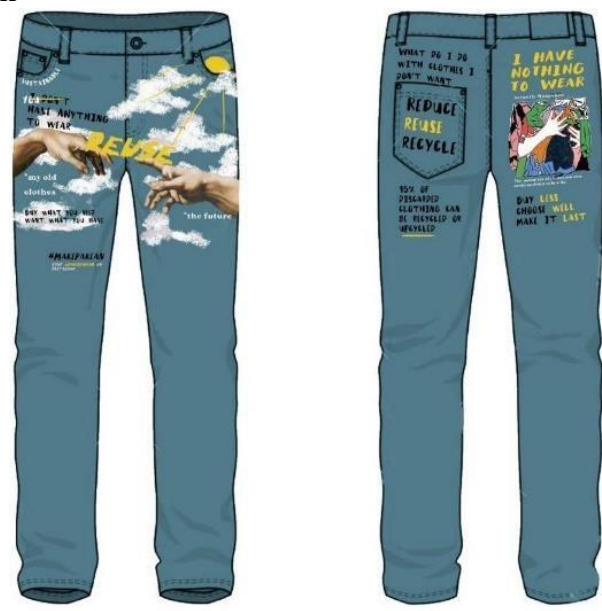

Gambar 3. Mock Up Sketsa 1
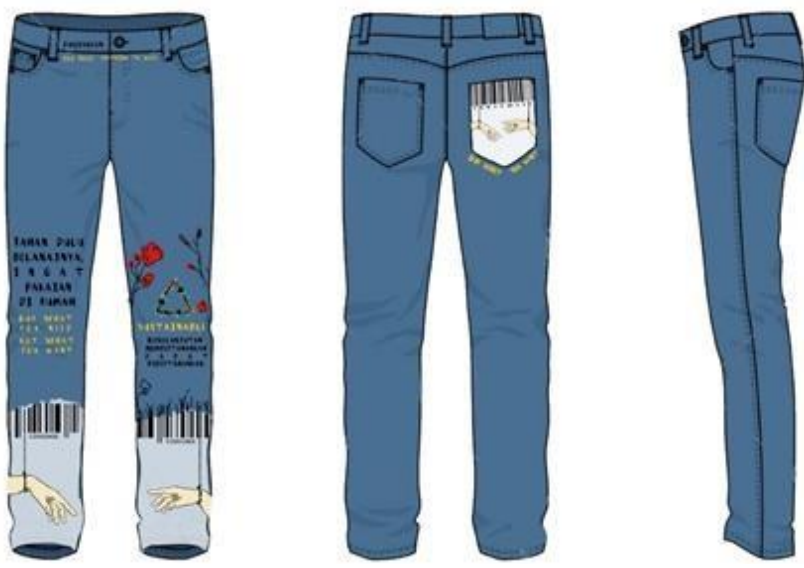

Gambar 4. Mock Up Sketsa 2 
KREATIF(Jurnal Karya Tulis, Rupa, Eksperimental dan Inovatif)

Vol. 03 No. 01 Juni 2021

P-ISSN: 2746-4369 || E-ISSN: 2714-9978

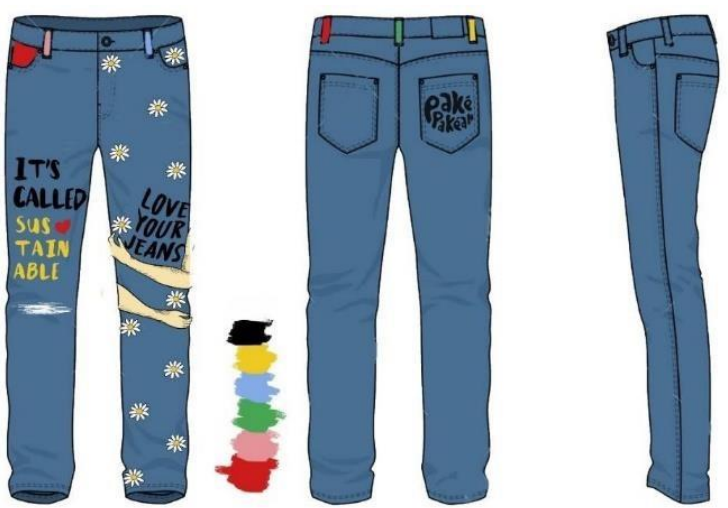

Gambar 5. Mock Up Sketsa 3

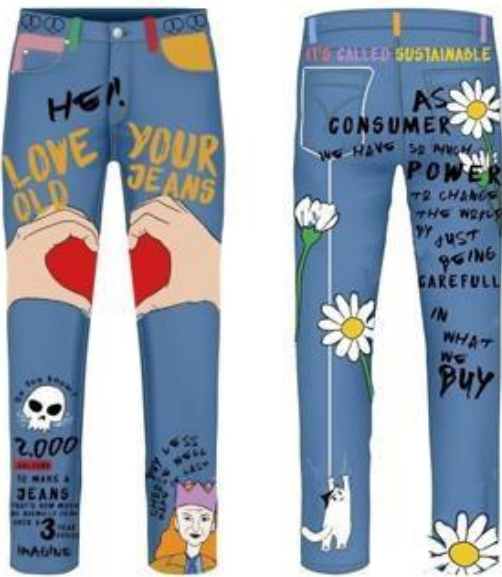

Gambar 6. Mock Up Sketsa 4

\section{KESIMPULAN}

Perancangan ini ditunjukan untuk kalangan remaja perempuan usia 18-21 tahun di Kota Bandung, bertujuan untuk menginformasikan mengenai sustainable fashion kepada target audience dengan menggunakan teknik upcycled berupa ilustrasi pada celana jeans tidak terpakai. Media kampanye dibuat dengan manual menggunakan ilustrasi hand painting melalui cat akrilik, fabric medium dan spidol kain. Dalam proses pengerjaannya,karya ini diawali dengan moodboard, gambar sketsa secara digital, membuat gambaran sketsa pada material jeans, dan memberi warna pada material celana jeans. Jeans dipilih karena produk fesyen ini sering digunakan oleh banyak orang, salah satunya oleh kalangan remaja perempuan usia 18-21 tahun di Kota Bandung. Selain itu menyampaikan informasi menganai sustainable fashion, media ini digunakan untuk mengajak target audience menggunakan kembali pakaian lama yang tidak terpakai, agar usia pakai dari pakaian tersebut dapat berjalan kembali.

\section{REFERENSI}

[1] https://historia.id/urban/articles/mengapa- bandung-dijuluki-parijs-van-java-P4WoZ pada 18 Juni 2020.

[2] Eni Lestarina. "Perilaku Konsumtif Dikalangan Remaja”, Jurnal Riset Tindakan Indonesia Vol. 2 No. 2, 2017, Hal 2.

[3] Venus, A. Manajemen Kampanye Panduan Teoritis dan Praktis Dalam Mengefektifkan Kampanye Komunikasi Publik (R. K. Soenendar (ed.); Revisi Per). Simbiosa Rekatama Media. 2018.

[4] Barnard, M. Etimologi dan definisi fashion dan pakaian. In I. S. Ibrahim (Ed.), Fashion Sebagai Komunikasi (p. 33). Jalasutra. 2011

[5] https://kbbi.kemdikbud.go.id/entri/Pakaian

[6] https://kbbi.kemdikbud.go.id/entri/Remaja 